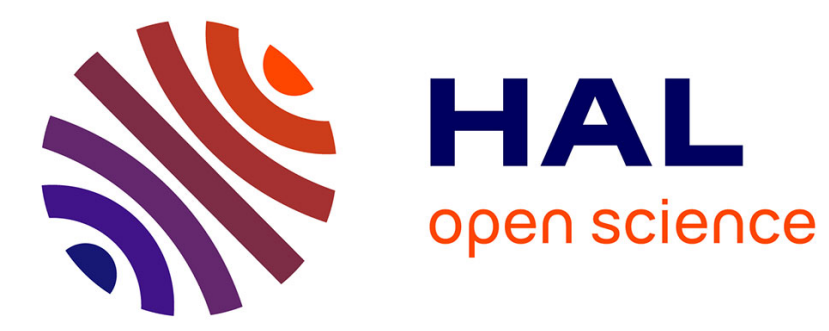

\title{
Characterizing the Context of Use in Mobile Work
} Heli Väätäjä

\section{To cite this version:}

Heli Väätäjä. Characterizing the Context of Use in Mobile Work. 4th IFIP 13.6 Working Conference on Human Work Interaction Design (HWID), Jun 2015, London, United Kingdom. pp.97-113, 10.1007/978-3-319-27048-7_7 . hal-01371791

\section{HAL Id: hal-01371791 \\ https://hal.inria.fr/hal-01371791}

Submitted on 9 Nov 2016

HAL is a multi-disciplinary open access archive for the deposit and dissemination of scientific research documents, whether they are published or not. The documents may come from teaching and research institutions in France or abroad, or from public or private research centers.
L'archive ouverte pluridisciplinaire HAL, est destinée au dépôt et à la diffusion de documents scientifiques de niveau recherche, publiés ou non, émanant des établissements d'enseignement et de recherche français ou étrangers, des laboratoires publics ou privés. 


\title{
Characterizing the Context of Use in Mobile Work
}

\author{
Heli Väätäjä \\ Tampere University of Technology, Finland \\ heli.vaataja@tut.fi
}

\begin{abstract}
The context of use has been widely acknowledged as important when designing and evaluating systems for work related activities. This paper describes in case of mobile news making the synthesized findings on the context of use. Findings are categorized to five components and nineteen subcomponents and characterized with examples from our studies. The presented findings validate a previously presented model for context of use in mobile HCI, extend it, and elaborate the definitions for the components. The presented elaborated model can be applied by academics and practitioners in development, research and evaluation activities from identifying requirements to evaluating systems for mobile work. Findings support understanding what circumstances and how they can contribute to user experience and acceptance of designed systems.
\end{abstract}

Keywords. Context of use, mobile, user experience, model, component, work.

\section{Introduction}

The importance of understanding and characterizing the context of use when designing and evaluating systems for work activities and their user experience has been widely acknowledged. In this research we approach context of use as the circumstances under which the activity [of mobile work] takes place (adapted from [1]). Mobile work is characterized by flexible use of time and place [2], that is, a person is able to move and carry out tasks "anytime and anywhere" [2],[3, p.14] with the help of wired or wireless technology [3, p. 14]. However, relatively little research exists that explicitly concentrates on the characteristics of context of use in mobile work.

This paper addresses mobile news making as an example of mobile work. Mobile news making activity takes place in a mobile context of use by using mobile handheld technology, in this research smartphones, in one or several subactivities in the news making process. News making consists of four main activities: 1) discovering the potential news item [4], 2) gathering the news material [4], [5], 3) news production [5], and 4) distribution [5]. These activities can be sequential or simultaneous [5]. They can be carried out at the spot of the event with mobile handheld devices by a mobile reporter, or specific activities, such as discovering and gathering can be done at the spot while others can be carried out in a café or by editors in the news room.

Mobile workers are "employees that work at and move between different places" $[6$, p.6]. In mobile news making mobile workers refer to 1) employees of the news organization [7], 2) other professionals in the news industry, such as freelancers that work, for example, for the news organization on event based contracts [7] or indenpendently or with crowdfunding, or 3) mobile crowdworkers [8] or reader reporters, who carry out news reporting related tasks based on the news organization's initi- 
ative with open, coordinated, or focused calls for content, expertise, or reports [9], or 4) citizen journalists working alone or in small groups outside of news organizations.

This paper synthesizes findings reported in twelve publications based on twelve case studies carried out in the context of mobile news making, characterizing the components and subcomponents of context of use. The findings validate the model of context of use for mobile HCI, CoU-MHCI model [10], extend it, and elaborate the definitions for the components. The presented elaborated model can be applied by academics and practitioners when designing and evaluating systems for mobile work that utilize location technologies or context-awareness, such as for identifying typical combinations of context characteristics. Findings also support understanding how circumstances can contribute to user experience and acceptance of the systems when planning system uptake and selecting solutions for use.

The paper is organized as follows. First, related work on characteristics of mobile context of use is summarized and user experience is discussed. Then, the methods and results are presented. The paper ends with conclusions and proposes future work.

\section{Related work}

The model for the context of use for mobile HCI, CoU-MHCI model [10], synthesizes findings from on an extensive literature review of components and characteristics of context of use. It describes five context components with their subcomponents and properties for the mobile context of use: 1) physical, 2) temporal, 3) task, 4) social, and 5) technology and information. As this model is one of the most comprehensive models for the context of use presented in the field of mobile HCI and it specifically addresses the mobile context of use, it is used as the framework for categorizing the related work, as well as the findings from our research discussing them in this paper.

Table 1. Characteristics of the mobile context of use for mobile work from prior literature.

\begin{tabular}{lll}
\hline Component & Characteristic & Reference(s) \\
\hline Task & Parallel primary task & 12,13 \\
& Multi-tasking & 14 \\
& Handling of other physical objects simultaneously & 13 \\
& Evolving tasks based on locality and situation & 15 \\
& Task complexity, irregularity & $16,17,18$ \\
& Task interdependence & 16 \\
Temporal & Work in dead time, in transit, in waiting & 19 \\
& Available time span & 19,20 \\
& Time-criticality, time-pressure, deadlines, urgency & $12,21,15,18,14$, \\
& & $22,16,25$ \\
Physical & Time of day & 14 \\
& Hours of work - extended \& unpredictable & 23 \\
& Environmental conditions & 14 \\
& Location & 23 \\
& Dynamic environment & 24 \\
Social & Interruptions & 20,23 \\
Technology and & Location dependence of the task & 16,25 \\
information & Frequency of mobility & 16 \\
\hline
\end{tabular}


The results of the summarization of related work is presented in Table 1 and briefly exemplified in the following.

Usage of mobile handheld devices in a mobile context of use is characterized by distractions, interruptions, and fragmented attention [20; 13; 24; 27]. Distracting characteristics of the mobile context of use, such as reflections on the screen and parallel tasks can influence user experience [28]. The split visual resources when interacting with the mobile devices (tapping with a stylus on a PDA) and walking, simultaneously trying to maintain an awareness of the environment, increases the task completion times, error rates, and work load, as well as reduces walking speed [29].

In relation to task context, the task hierarchy and task characteristics are important. The primary task, such as observing animals [24] or focusing attention on other tasks external to the mobile device: to avoid danger, to monitor progress, or to handle other objects [13], may call for a high level of attention and limit the use of hands for interaction with the mobile device. Multi-tasking, such as communicating on the phone while pursuing a target in police work, splits the attention of the user [14]. The fragmented attention caused by context characteristics, including interruptions (physical context), parallel tasks, multi-tasking, and the handling of other objects related to the task at hand, needs to be considered when designing for the mobile context of use.

The characteristics of temporal context, including, time-criticality of action, urgency, deadlines, and time-pressure, is emphasized in mobile work. In the case of freelance work, the hours of work are described as unpredictable and extended [23]. The physical context characteristics include environmental conditions, location, and dynamism of the environment, as well as interruptions, e.g., caused by traffic lights in police work. In relation to the technology and information context, availability and access to technology and information, and their uncertainty in a mobile context of work, or alternatively the opportunities offered by technology and available information has been emphasized. Finally, in relation to social context, bystanders affect the comfort of using mobile systems, as users consider whether bystanders experiencing the use of the system find it appropriate to the situation such as in case of firefighting [12]. Also, in the case of police work, unobtrusiveness and discreteness of using mobile systems can contribute to experience of users [14]. From the five components of context of use, social context has received relatively little attention in literature of mobile work.

\section{$3 \quad$ User experience and news making}

User experience is described as subjective, situated, complex and dynamic [30]. According to Hassenzahl et al. [30] context within which the interaction occurs is one of factors that contribute to user experience. In our research we found that the mobile context of use and its characteristics are one of the four components contributing to user experience [31]. The three other components contributing to user experience include the characteristics of the user, system and the outcome of using the mobile system as illustrated in Figure 1 (see also [31, p. 94]). The fifth component in the model of user experience in mobile news making presented in Figure 1 are the user's verbally expressible descriptive attributes related to his/her experience in terms of 
system and outcome quality and the perceived impacts. They can contribute to overall evaluative judgments. The impressions and perceptions of system and outcome quality, the perceived impacts, and the overall evaluative judgments can lead to consequences that can be moderated by the characteristics of the user, system, the context of use and the outcome.

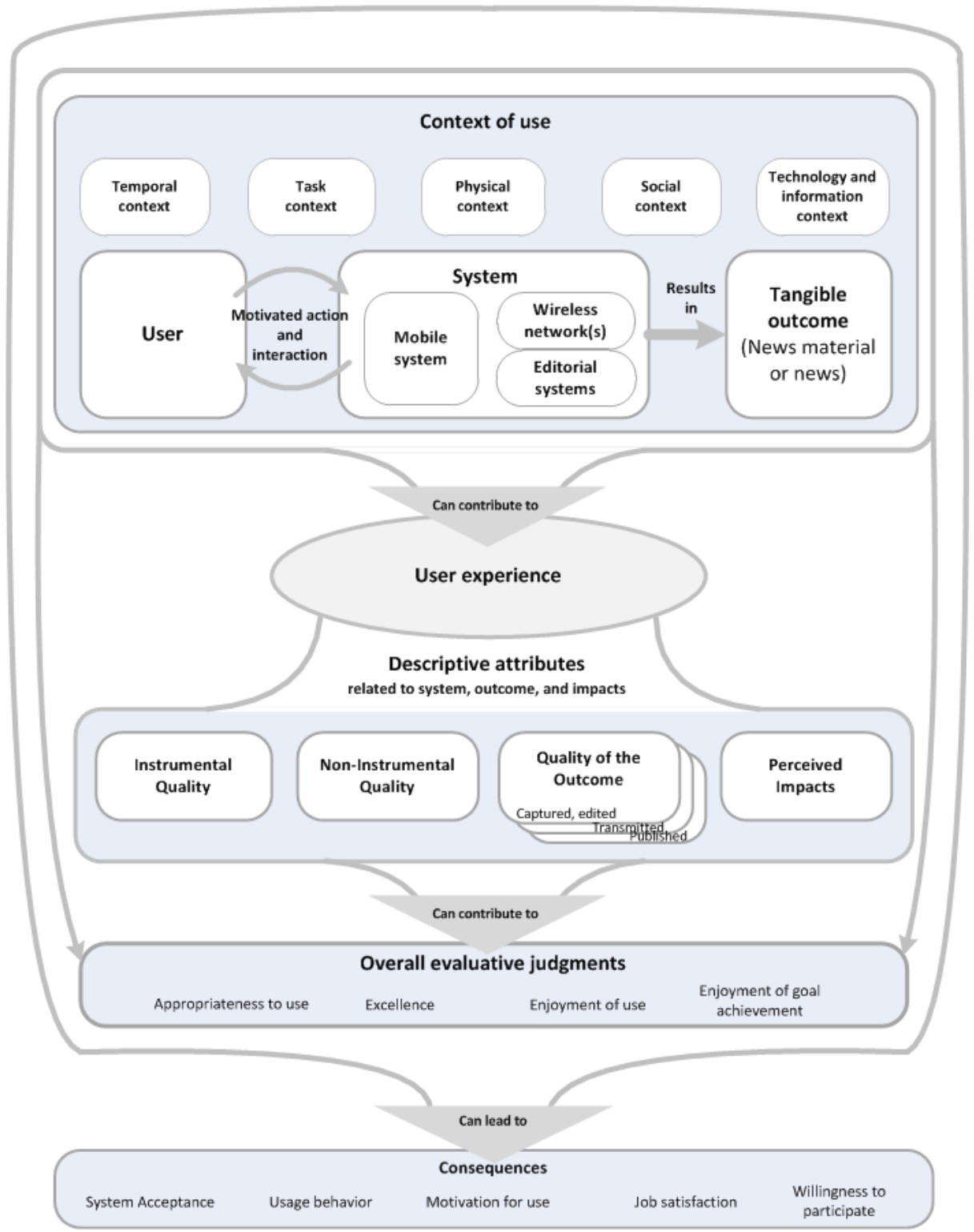

Fig. 1. The model of user experience in mobile news making (modified from [31, p. 94]) 
To understand user experience in mobile news making, it is essential to understand the activity of news making and the context of the activity. The goal of news making is to publish news, share information, and tell a story. These stories are told to an audience. News are a selective version of world events with a focus on what is new or unusual.

Two types of news are often described. Hard news is new, timely information about significant events, describing factual details of what has happened or what has been said [32, p. 12], [33, p. 24]. Examples of this type of news are natural catastrophes, major accidents, or important political events. Soft news can be characterized as lighter, more colorful and entertaining (ibid.). They may neither be immediately important nor informative (ibid). Reporting a local community event could be an example of this type of news.

Journalists measure the news worthiness of potential news items against criteria that are known as news values, such as relevance for the audience, timeliness, and novelty. Technology that is used in news making needs to support its goals and the criteria that are used in assessing the news worthiness and journalistic quality. On the other hand, the selection of news is constrained and influenced by a number of structural factors, such as legal constraints, the system of media ownership, organizational routines, a shortage of time and market forces [34, pp. 17-34]. All of these factors exemplify what influences news making and are related to the concept of context.

How does the context of use contribute to user experience in mobile news making? Let's consider an example. The goal of news reporting is informing the public about current issues. Examples of requirements and values in news journalism are timely and truthful reporting. Constraints set by the organization are deadlines, or required immediacy of reporting directly from the spot of the event. The available technology and information available for a mobile reporter to carry out news making creates possibilities and at the same time may set constraints to the activity and quality of outcome. The ideals, needs and goals of a mobile reporter may have different importance for the mobile reporter depending on the situation. Situation, defined as the "relative position or combination of circumstances at a certain moment" (Merriam-Webster, retrieved 5.8.2013) as a combinations of previous examples when using the smartphone-based system in news making activity is one factor that can contribute to user experience in this domain.

We have defined user experience in mobile news making as follows (see Figure 1 and [31, p. 91]): "User experience is the consequence of motivated action and interaction with the system that has goals specified by the user, organization, and other stakeholders, as well as by the circumstances within which the activity takes place. The experiential components of user experience include user's impressions and reactions related to the system, the tangible outcome of system use, and the impacts of the system, and overall evaluative judgments. The characteristics of the user, system, the context of use and the tangible outcome can contribute to user experience." In the following sections, the methods and findings on mobile work context from our user experience studies in mobile news making with smartphones are presented. 


\section{$4 \quad$ Methods}

This paper presents a synthesis of findings for mobile context of use from twelve case studies carried out in the context of mobile news making that are reported in twelve scientific publications: [37], [38], [39], [40], [41], [7], [42], [9], [43], [44], [45], [46]. The twelve empirical studies were carried out to explore user experience, its components, and collaborative processes when using smartphones in mobile newsmaking. The reported findings from the studies presented in the twelve papers were categorized to the components and subcomponents of the CoU-MHCI model [10]. Two new subcomponents were created to describe themes that did not fit to the existing subcomponents. Definitions for the components of context of use were elaborated based on our findings and characteristics for the components and subcomponents are presented.

The emphasis of the research approach of the twelve case studies is qualitative with observations, interviews and focus groups as the main methods of inquiry. The emphasis on qualitative research stems from the goal of understanding the explored phenomenon and technology use in the natural context of use, aiming to find explanations and provide interpretations inductively from multiple sources of data and from multiple perspectives in order to establish patterns and themes (Creswell, 2007, p. 37). Although the emphasis was on qualitative strand, combinations of qualitative and quantitative strands were used in most of the case studies. Mixed methods research designs provide a more comprehensive and more complete account of the area of the research and understanding of the context, enabling finding explanations for the findings, as well as augmenting the findings of one strand by the other strand (Bryman, 2008b).

Seven of the case studies were carried out as field studies, two as quasiexperiments in field conditions, two as interview studies, and one as a participatory focus group study. Field studies were chosen for the case studies when there was a possibility to gain access to studying news reporting in the mobile context of use. This enabled understanding of news making practice in context in addition to usage, experiences and requirements for mobile systems. Quasi-experiments enabled the study of user experience with news reporting tasks carried out with smartphones in the natural context of use, but using predefined reporting assignments created by the researchers, which was not possible in other studies conducted in field settings.

Seven of the twelve case studies include the usage of a mobile service client for news making in the mobile context of use. In six of the seven case studies the used client was a partly or fully functional prototype. Two of the twelve studies concentrate on reader participation in news making as a form of mobile crowdsourcing. The rest of the studies focused on professional use. Over one hundred participants participated in the studies. Majority of the participants were students of visual journalism with prior work experience in journalism to ensure experience as close to professional users as possible. On the other hand, it was not possible to use prototypes in professional's daily use with deadlines due to the possible unreliability of the prototypes. Within their journalism studies the students were reporting news in as close to authentic context of use as possible enabling us to study real news reporting situations. 
A more detailed description of the methods of the twelve case studies can be found in the publications and in [31, pp. 46-59].

\section{$5 \quad$ Findings on context of use in mobile news making}

We categorized the findings on the factors of context of use that influence user experience in mobile news making to the five context components (temporal, task, physical, social, and technology and information context) and their subcomponents according to the CoU-MHCI model [10]. Our findings validate the model, and elaborate the definitions for its components in the case of mobile news making. In addition, our findings extend the model by two subcomponents. First, task context is extended with mobile assignment characteristics. Second, social context is extended by stakeholders, such as colleagues, editors, readers, or customers, who are not physically or virtually present when interacting with the device, but who assess the quality of the news material and reporting.

\subsection{Temporal context}

Temporal context refers to the interaction and carrying out the activity with the mobile system in relation to time and it captures the nature of the activity in terms of time (adapted from [10]).

Table 2. Summarized findings on the temporal context.

\begin{tabular}{ll}
\hline Findings related to the subcomponents & Publication(s) \\
\hline Duration - the length of interaction, activity, or the event in which interaction & \\
takes place & $41,7,44$ \\
Time (delay, response time) to start up photo and video recording & $37,38,41,7,42,9,43,44$, \\
Time spent on the activity, task or carrying out a sub-activity, such as record- & 45 \\
ing, editing,submitting & \\
Time of day, week, and year & $37,38,7,42$ \\
$\begin{array}{l}\text { Deadline, schedule, or continuous deadline } \\
\text { When the mobile reporter is available for locating and receiving mobile as- }\end{array}$ & 42,43 \\
signments & \\
Before, during and after & $41,7,44,46$ \\
Preparations for capturing, editing, and submitting & 42,45 \\
$\begin{array}{l}\text { Following up on submission, calling up the newsroom after submission to } \\
\text { check on the success of mobile delivery }\end{array}$ & \\
The action's relation to time & $37,38,41,7,42,44,45$ \\
Hurried, waiting, speed, urgency, time pressure & 37,38 \\
The unexpectedness of events that call for action & 42 \\
Synchronism (synchronous-asynchronous) & \\
Communication by phone calls, SMS, MMS, email, chat, mobile assignments & 42 \\
\hline
\end{tabular}

Temporal context is characterized by 1) duration - the time spent on the interaction, activity, subactivity, or task, 2) time of day, week, or year of the interaction, activity or task, 3) actions prior, simultaneously, or after the interaction with the mobile system or activity carried out with it, 4) the action's relation to time, and 5) synchronicity or asynchronicity of communication (Table 2). Time is one of the key characteristics related to news making. The work is time critical and calls for immediate publishing of breaking news or often directly from the spot of the event in mobile context of use 
to be competitive and relevant to the audience. This applies to professionals, reader reporters and citizen journalists alike. On the other hand, reporting in organizational context or by pro-amateurs is also carefully planned, scheduled and organized days, weeks or months ahead of known events, such as elections etc. When a surprising event occurs, it can change the plans and calls for immediate action and attention interrupting the current activity. Temporal context is therefore related to the news qualities in terms of immediacy, unexpectedness, and timeliness of news. According to described experiences by participants in our studies, the capability of the system to support the time-related needs and constraints, and the aimed news qualities related to time can have a major influence on user experience.

\section{$5.2 \quad$ Task context}

Task context refers to the user's tasks and activities surrounding the interaction with a mobile system or when carrying out the activity with the system (adapted from [10]). Synthesized findings on subcomponents (multi-tasking, interruptions, task domain, and assignment characteristics) are presented in Table 3.

Table 3. Summarized findings on the task context.

\begin{tabular}{|c|c|}
\hline Findings related to the subcomponents & Publication(s) \\
\hline \multicolumn{2}{|l|}{$\begin{array}{l}\text { Multi-tasking - multiple parallel tasks alongside human mobile computer interac- } \\
\text { tion that compete for cognitive resources }\end{array}$} \\
\hline $\begin{array}{l}\text { Primary task interviewing, secondary task recording audio, photo, and video footage, } \\
\text { or writing notes with the smartphone }\end{array}$ & $41,44,45$ \\
\hline Keeping track of the number of characters in the story while writing & 44,45 \\
\hline Keeping track of time and the deadline & 44 \\
\hline $\begin{array}{l}\text { Awareness of the surrounding physical conditions or constraints of the used } \\
\text { smartphone that need to be taken into account when shooting footage (photo, video) } \\
\text { or recording audio }\end{array}$ & $39,41,7,44,45$ \\
\hline $\begin{array}{l}\text { Parallel tasks while receiving mobile assignments (no parallel task, during free time, } \\
\text { when working or studying) }\end{array}$ & 42,43 \\
\hline \multicolumn{2}{|l|}{$\begin{array}{l}\text { Interruptions - events that break the user's attention from the current task to focus } \\
\text { on the interruption temporarily }\end{array}$} \\
\hline 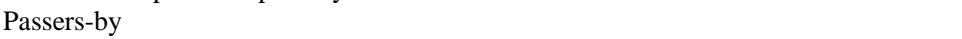 & 38 \\
\hline $\begin{array}{l}\text { Interruptions by bystanders who make contact while the reporter is editing at a public } \\
\text { location }\end{array}$ & 38,46 \\
\hline The primary task is interrupted by a mobile assignment & 43 \\
\hline \multicolumn{2}{|l|}{$\begin{array}{l}\text { Task domain - macro level of task context by dividing the situation of an interac- } \\
\text { tion into two groups - goal-oriented (work) and action-oriented (entertainment) tasks }\end{array}$} \\
\hline $\begin{array}{l}\text { Primarily goal-oriented for professionals, but can include action-oriented characteris- } \\
\text { tics }\end{array}$ & $37,38,41,7,42$ \\
\hline $\begin{array}{l}\text { Primarily action-oriented for readers, but can include goal-oriented characteristics } \\
\text { Assignment characteristics (added sub-component) }\end{array}$ & 9 \\
\hline $\begin{array}{l}\text { The type of assignment or reporting to be carried out or the content asked for and } \\
\text { attributes of content (no. of characters in text, length of audio and video footage, } \\
\text { count of photos, requested quality, special requests like camera angles) }\end{array}$ & 42,43 \\
\hline Monetary incentive, incentive mechanism & $7,9,43$ \\
\hline Voluntariness of carrying out the task & 9 \\
\hline Autonomy in reporting & 42 \\
\hline No. of receivers & 42 \\
\hline The creativity needed or allowed & 42 \\
\hline The needed skills and equipment & 42 \\
\hline
\end{tabular}


In our studies, multi-tasking included parallel tasks and activities, such as instances of interviewing while audio or video recording, or taking notes, for example. Mobile reporters also kept track of typed characters while writing if a specific length has been assigned for the story, as well as time, and possible deadline. When capturing photos and video footage, surrounding physical circumstances needed to be taken into account to ensure the sufficient technical quality of the footage. This may call for action from the users, such as turning on lights indoors, choosing an appropriate direction for shooting footage based on direction of natural light or taking into account the ambient noise conditions. Parallel other ongoing tasks and activities also contribute to the willingness to receive mobile assignments for reporting.

Interruptions are one of the important subcomponents of the task context as they influence the activity carried out. As the mobile reporters typically work in public spaces, there may be interruptions due to passers-by, or bystanders may take contact and talk to the mobile reporter and interrupt the task being carried out.

On macro-level the task context is suggested to be divided to goal-oriented tasks in work related use and action-oriented tasks for entertainment [10]. In mobile news making, for professionals the tasks are primarily set by the organization or customer, but secondarily, the tasks may include action-oriented elements that could be related to concepts such as flow and enjoyment of the activity as such. For reader reporters participating to news making the enjoyment of the activity may be the primary motivation to participate. Participation of readers may, however, also include elements related to goal-oriented activity and motivations that professionals have or combinations of motivations as our later studies in using crowdsourcing in mobile news making indicate. The goal-oriented task setting may also apply to crowdsourcing, if the participation is primarily motivated by monetary benefit and has no hobbyist or enjoyment, or other motivational element.

The assignment characteristics, whether delivered as mobile assignments to the smartphone, e.g., via specific applications, email, or SMS messages, or received more traditionally, were added as a new subcomponent. Assignment characteristics frame the properties of the task context, and was addressed in our studies especially when studying use of mobile assignment delivery, carrying them out, and responding to them, but also in our other studies. Identified assignment characteristics include the types of assignment, reporting, and content or its attributes, the perceived voluntariness of undertaking and carrying out the assignment, the perceived and expressed extent of autonomy and creativity, needed skills or equipment as well as the incentives. Assignment characteristics can also contribute to user experience by moderating the willingness to undertake tasks and be motivated by the goal and activity.

\subsection{Physical context}

Physical context refers to apparent features or physically sensed circumstances while interacting with the system or carrying out the activity with it (adapted from [10]). Its components include 1) spatial location, functional place and space, 2) sensed environmental attributes, 3) movements or mobility, and 4) artefacts (Table 4). 
Table 4. Summarized findings on the physical context.

\begin{tabular}{|c|c|}
\hline Findings related to sub-components & Publication(s) \\
\hline \multicolumn{2}{|c|}{$\begin{array}{l}\text { Spatial location, functional place and space - the aspects of location and material } \\
\text { characteristics of location, functional space and in distance participation }\end{array}$} \\
\hline Geographical location (vicinity or distance) & $38,42,43,44,45$ \\
\hline Third workplaces - cafés, hallways, canteens, waiting halls etc. & $37,38,44,45$ \\
\hline The precision of locating mobile reporters & 42,43 \\
\hline $\begin{array}{l}\text { Attributes related to the area, location or country such as shady, totalitarian, unac- } \\
\text { ceptable place, safe, dangerous }\end{array}$ & 42,43 \\
\hline \multicolumn{2}{|l|}{ Sensed environmental attributes } \\
\hline Light, lighting & $38,41,44,45$ \\
\hline Temperature & 38 \\
\hline Ambient noise, sounds & $38,44,45$ \\
\hline \multicolumn{2}{|c|}{$\begin{array}{l}\text { Movements and mobility - the position and motion of the user's body, the mobili- } \\
\text { ty of the user and the motion of the user's physical and functional environment }\end{array}$} \\
\hline Sitting while editing, reaching out to record footage & 38,41 \\
\hline $\begin{array}{l}\text { Placement of artefacts in relation to the user's body (e.g. on the knee, on a table, on } \\
\text { a sofa) }\end{array}$ & 38,44 \\
\hline Working while commuting & 7 \\
\hline \multicolumn{2}{|l|}{ Artefacts - physical objects that surround a human-mobile computer interaction } \\
\hline Proximity of artefacts (e.g. a notebook) & 44 \\
\hline Chairs, sofas, tables & 38,44 \\
\hline
\end{tabular}

Mobile reporters work in multiple workplaces and dynamic locations. The work is often carried out in public spaces, either outside or inside. Stationary workplaces, which can be called third workplaces [3], include cafés, or waiting rooms, for example. Typical mobile workplaces are also trains, cars or airplanes, where planning the upcoming reporting or editing the materials can be carried out. The proximity of the reporting spot to the reporter's current location as well as the precision of locating mobile reporters can contribute to participation preferences in case of assignmentbased processes. The sensed environmental attributes such as lighting, temperature and ambient noise can contribute to carrying out the activity and influence the capturing of photos and video footage. The quality of the outcome can then be influenced by the combination of the system characteristics and environmental attributes contributing to user experience, for example. Furthermore, the perceived characteristics and verbal descriptions of the area, location, or country (such as totalitarian, safe, shady) were found to be related to perceived privacy and safety issues and willingness to share location information, when studying locating reporters and location-based assignments.

Physical context is also characterized by movement of the user's body while interacting with the system. User may be sitting or standing while writing, capturing photos or video footage, or kneeling or reaching out while using the system for capturing photo or video footage. The tools may be placed on the user's body such as on the lap or attached to arm, or placed on surrounding objects, such as on a table or sofa. Furthermore, smartphones were in some instances attached to surrounding other objects, such as a book, a bike or a window for photo or video capture enabling new ways of content capture and reporting. 


\subsection{Social context}

Social context refers to other persons present physically or virtually while interacting with the system or using it for the activity, or to other stakeholders of the activity who perceive and assess its outcome (adapted from [10]). Subcomponents include 1) persons present in the situation, 2) stakeholders not physically or virtually present, and 3) culture (Table 5).

Table 5. Summarized findings on the social context.

Findings related to subcomponents Publication(s)

The persons present in the situation classified to self, group, organization or public, physically or virtually present.

Interviewees, bystanders, peers (colleagues) present while interacting with the $37,38,39$ smartphone-based system

Stakeholders not physically or virtually present while user interacts with the device or carries out the activity to produce an outcome (added sub-component)

Editors, colleagues in the newsroom or from another newsroom, customers, audience/readers who asses the quality of the produced material or news (stories)

Culture - The macro level of social context including the values, norms, and attitudes of a certain culture, such as the work and organizational culture

Journalistic and news values, norms etc.

Profession related values, identity, ideal, norms etc.

Persons physically present while interacting can include interviewees, bystanders, and own colleagues or peers of the mobile reporter. Newsroom staff or a colleague working elsewhere in the field can be virtually present using synchronous (e.g. video or online calls) or asynchronous means of communication (instant messaging or social media services). Other stakeholders may also not be physically present, such as freelancer's customers or the audience that consumes the news. The opinions and anticipated impressions and expectations of persons present or of other stakeholders on the used mobile system and the outcome of its usage can influence the user experience of a mobile reporter. The social acceptance of the used tool is important for users and it may differ based on the user group. Social acceptance may also change over time. What is considered a low-quality system, odd, and even shameful at first, may become part of everyday work practice within a few years as technology matures and is adopted to use providing new opportunities and value for the users as well as audience in case of news reporting. Furthermore, culture and practice of journalism and participatory journalism or the culture of the organization in question incorporate values, norms and ideals, that can as a subcomponent contribute to user experience.

\subsection{Technology and information context}

Technology and information context refers to the relation of other relevant systems and services to the user's interaction or activity with the mobile system. It includes as subcomponents 1) other systems and services, 2) interoperability between and across devices, and 3) informational artefacts (Table 6).

In case of journalism, other systems or services can include external components to the core mobile system, such as microphones, keyboards, and displays, or alternatively, mobile applications or services that can be used for mobile journalism. It also includes the wireless network with its attributes as well as the interoperativity of sys- 
tems in transferring data or material from one device to another or to the editorial system. Paper notebooks with hand-written information on preparations, interview questions, and interviewee's quotes as well as plans for editing video footage can still be important informational artefacts for mobile reporters. In addition, smartphones enable, with the available connectivity to the Internet, access to open information or organization's archives, for example. The multipart and complex systems form ecosystems of devices and services that can contribute to user experience when used in mobile newsmaking.

Table 6. Summarized findings on the technology and information context.

\begin{tabular}{ll}
\hline Findings related to subcomponents & Publication(s) \\
\hline Other systems and services - the device, applications and the network related to the & \\
user's system or service (note: in this study components external to the smartphone or & \\
installed after purchase on the smartphone) & \\
External components of a smartphone-based system, such as microphones and keyboards. & $38,41,44,46$ \\
Mobile journalism related applications & $37,41,7,42,9$ \\
The wireless network and related attributes (availability, reliability, speed, interference) & $37,38,41,7$ \\
Interoperability between and across devices & \\
Transferring data from one device to another or material delivered from the mobile system & $44,45,46$ \\
to the editorial system & \\
Informational artefacts and access to other artefacts that contain relevant information & \\
Notebooks & $37,38,7,9$ \\
Access to information via the Internet & 7 \\
\hline
\end{tabular}

\subsection{Properties of the mobile context components in mobile news making}

The model for context of use for mobile HCI, the CoU-MHCI model [10], describes four properties for context components. These properties are 1) the level of magnitude varying from micro to macro, 2) the level of dynamism varying from static to dynamic, 3) the patterns varying from rythmic to random, and 4) typical combinations of context components [10]. These are exemplified next in case of mobile news making.

The findings on the level of magnitude for the five context components in mobile news making can be mapped to three levels: macro-, meso-, and micro-level (see for levels of analysis [48]). Macro-level exemplified for social context refers to the context of news journalism with its journalistic standards, values, practices, ethical codes and goals as well as its role in the society and the community it is reporting to. Mesolevel refers in case of social context to the organization, community of practice or peer group. Micro-level context of use is the individual level, referring to the situation and its characteristics when a mobile reporter is interacting with the system and using it while carrying out the activity of news making. All levels can contribute to user experience of a mobile reporter, by framing goals, requirements, possibilities, or constraints for mobile news making.

The level of dynamism varies from static to dynamic in the components of context of use in mobile news making. Activity within which the interaction with the mobile system occurs may be hurried or waiting. Breaking news bring urgency to news making, calling for reporting and publishing immediately from the spot of the event and changing the rhythm on the go. To be able to "capture the moment" needs fast action and undelayed recording of photo and video footage. Fast movement, 
changes in the environmental conditions, such as lighting and ambient noise, may need attention and adjustment when shooting of photo and video footage. The network availability and speed of connection may vary depending on the crowdedness of the area or movement of the mobile reporter. Dynamism in the context of use needs to be supported by the mobile system and its features and functionalities.

The patterns in mobile news making can have a regular rhythm, or occur randomly. A regular workday with a priori set plan and deadlines brings regularity to the workdays of professionals. As random events and happenings worthy of news reporting, such as breaking news about a big natural catastrophe or accident, unfold, the regular schedule breaks. In our studies we also noticed, that there are certain types of news stories, that are dependent on the time of year or have some other rhythm based on the public holidays, or national or local elections, for example. The locations of mobile news making and types of stories can also have patterns, like focusing on local issues from a certain area at a certain time of the week or month. Randomly happening unexpected events, and on the spot reporting seem to fit the capabilities and strengths of smartphone-based systems in news making.

Finally, typical combinations of context components with properties can be identified for mobile news making. Based on our observations, the combinations typically include all five context components, but their importance and emphasis can vary depending on the situation. The situation described by the combination of circumstances can influence the requirements and needs of a mobile user and therefore contribute to user experience in a particular situation.

\section{Conclusions}

Findings related to five components of context of use (temporal, task, physical, social and technology and information context) with a total of nineteen subcomponents were reported in case of mobile news making. Two subcomponents were added to the original CoU-MHCI model [10]. Task context was extended with assignment characteristics, and social context by stakeholders who are not physically or virtually present when interacting with the device, but who assess the quality of the news material and reporting. Situation as circumstances described by a combination of components, subcomponents and properties of context of use, can have significance for the users that influences their evaluation of the system quality and its appropriateness to use. The findings illustrate context of use related components and characteristics that can influence user experience in the field of mobile news making. Further studies could address the context related characteristics in other work domains to test and extend the model. The context model and presented findings can also be used as a framework in planning of studies, data collection, and measurement of context related aspects.

\section{$7 \quad$ References}

1. Roto, V.: Web browsing on mobile phones - Characteristics of user experience. Doctoral dissertation. TKK Dissertations 49, Helsinki University of Technology (2006) 
2. Vartiainen, M., Hyrkkänen, U.: Changing requirements and mental workload factors in mobile multi-locational work. New Technology, Work and Employment, 25(2), 117-235 (2010)

3. Vartiainen, M.: Mobile virtual work - Concepts, outcomes and challenges. In: Andriessen, J. H. E., Vartiainen, M. (eds.) Mobile virtual work: A new paradigm? pp. 267-288. Springer, Heidelberg (2006)

4. Reich, Z.: The process model of news initiative. Journalism Studies, 7(4), 497-514 (2006)

5. Bradshaw, P.: Model for a $21^{\text {st }}$ century newsroom - redux. How digitization has changed news organisations in a multiplatform world. Leanpub. (2012) Available at: https://leanpub.com/s/0JmP8wqPD40vEznX1aNa5r.pdf

6. Andriessen, E., Vartiainen, M.: Emerging Mobile Virtual Work. In: J.H.E. Andriessen, M. Vartiainen (eds.) Mobile Virtual Work: A New Paradigm? pp. 3-12. Springer, Heidelberg. (2006)

7. Väätäjä, H.: Mobile work efficiency: Balancing between benefits, costs and sacrifices. International Journal of Mobile Human Computer Interaction, 4(2), 67-87 (2012)

8. Ross, J., Irani, L., Silberman, M.S., Zaldivar, A., Tomlinson, B.: Who are the crowdworkers?: shifting demographics in mechanical turk. In: Proc. CHI EA '10, pp. 2863-2872, ACM (2010)

9. Väätäjä, H., Vainio, T., Sirkkunen, E. \& Salo, K. 2011. Crowdsourced news reporting: supporting news content creation with mobile phones. In: Proc. MobileHCI '11, pp. 435444, ACM (2011)

10. Jumisko-Pyykkö, S., \& Vainio, T. Framing the context of use for mobile HCI. International Journal of Mobile Human Computer Interaction (IJMHCI), 2(4), 1-28 (2010)

11. Forsberg, K.: Navigating in the NewsSpace. In: Proc. CSCWD99. Pp. 329-336 (1999)

12. Bergstrand, F., \& Landgren, J.: Visual reporting in time-critical work: Exploring video use in emergency response. In: Proc. MobileHCI 2011, 415-424, ACM (2011)

13. Kristoffersen, S., Ljungberg, F.: "Making place" to make IT work: empirical explorations of HCI for mobile CSCW. In: Proceedings of the international ACM SIGGROUP conference on Supporting group work, pp. 276-285, ACM (1999)

14. Straus, S. G., Bikson, T. K., Balkovich, E., Pane, J. F.: Mobile technology and action teams: assessing BlackBerry use in law enforcement units. CSCW, 19(1), 45-71 (2010)

15. Fagrell H., Forsberg, K., Sanneblad, J.: FieldWise: a mobile knowledge management architecture. In: Proc. CSCW '00, pp. 211-220, ACM (2000)

16. Yuan, Y., Zheng, W. 2009. Mobile task characteristics and the needs for mobile work support: a comparison between mobile knowledge workers and field workers. In: Eighth International Conference on Mobile Business, ICMB 2009, pp. 7-11, IEEE (2009)

17. Gebauer, J. User requirements of mobile technology: A summary of research results. Information, Knowledge, Systems Management, 7(1), 101-119 (2008)

18. Gebauer, J., Shaw, M. J., Gribbins, M. L.: Task-technology fit for mobile information systems. Journal of Information Technology, 25(3), 259-272 (2010)

19. Perry, M., O'hara, K., Sellen, A., Brown, B., Harper, R.: Dealing with mobility: understanding access anytime, anywhere. ACM TOCHI, 8(4), 323-347 (2001)

20. Karlson, A. K., Iqbal, S. T., Meyers, B., Ramos, G., Lee, K., Tang, J. C.: Mobile taskflow in context: a screenshot study of smartphone usage. In: Proc. CHI'10, pp. 2009-2018, ACM (2010)

21. Chatterjee, S., Chakraborty, S., Sarker, S., Sarker, S., Lau, F. Y.: Examining the success factors for mobile work in healthcare: a deductive study. Decision Support Systems, 46(3), 620-633 (2009) 
22. Streefkerk, J.W., Van Ench-Bussemakers, M.P., Neerincx, M.A. Balancing costs and benefits of automated task allocation in mobile surveillance. In: Proceedings of the 28th Annual European Conference on Cognitive Ergonomics (ECCE '10), pp. 99-106, ACM (2010)

23. Sadler, K., Robertson, T., Kan, M. It's always there, it's always on: Australian freelancer's management of availability using mobile technologies. In: Proceedings of the 8th conference on Human-computer interaction with mobile devices and services, pp. 49-52, ACM (2006)

24. Pascoe, J., Ryan, N., Morse, D. Using while moving: HCI issues in fieldwork environments. ACM Transactions on Computer-Human Interaction (TOCHI), 7(3), 417-437 (2000)

25. Yuan, Y., Archer, N., Connelly, C.e., \& Zheng, W. 2010. Identifying the ideal fit between mobile work and mobile work support. Information \& Management, 47(3), 125-137.

26. Sørensen, C., Gibson, D. 2004.: Ubiquitous Visions and Opaque Realities: Professionals Talking About Mobile Technologies. INFO: The Journal of Policy, Regulation and Strategy for Telecommunications, Information and Media, 6 (3), 188-196.

27. Oulasvirta, A., Tamminen, S., Roto, V., Kuorelahti, J.: Interaction in 4-second bursts: The fragmented nature of attentional resources in mobile HCI. In: Proc. CHI '05, 919-928, ACM (2005)

28. Jumisko-Pyykkö, S. Utriainen, T.: A hybrid method for the context of use: Evaluation of user-centered quality of experience for mobile (3D) television. International Journal of Multimedia Tools and Applications, 1-41 (2010)

29. Lin, M., Goldman, R., Price, K. J., Sears, A., Jacko, J.: How do people tap when walking? An empirical investigation of nomadic data entry. International Journal of HumanComputer Studies, 65(9), 759-769 (2007)

30. Hassenzahl, M., Tractinsky, N.: User experience - a research agenda. Behaviour and Information Technology, 25, 2, 91-97 (2006)

31. Väätäjä, H.: Framing the user experience in mobile newsmaking with smartphones. Doctoral dissertation. Tampere University of Technology, Publication 1196 (2014) Available at: http://URN.fi/URN:ISBN:978-952-15-3270-2

32. Itule, B.D., Anderson, D.A.: News writing and reporting for today's media. McGraw-Hill (2007)

33. Sissons, H.: Practical Journalism: How to write news. SAGE, Great Britain (2006)

34. Harcup, T. Journalism: Principles and practice. Second ed., SAGE, Great Britain (2009)

35. Creswell, J.W., Plano Clark, V.L.: Designing and Conducting Mixed Methods Research. SAGE, USA (2007)

36. Bryman, A. Why do Researchers Integrate/Combine/Mesh/Blend/Mix/Merge/Fuse Quantitative and Qualitative Research? In: M.M. Bergman (ed.) Advances in Mixed Methods Research, pp. 87-100, SAGE, Great Britain (2008)

37. Väätäjä, H. User experience evaluation criteria for mobile news making technology: findings from a case study. In: Proc. OZCHI '10, pp. 152-159, ACM (2010)

38. Wigelius, H., Väätäjä, H. Dimensions of Context Affecting User Experience in Mobile Work. In: Proc.INTERACT 2009, part II, LNCS 5727. Pp. 604-617, Springer (2009)

39. Väätäjä, H., Koponen, T., Roto, V. 2009. Developing practical tools for user experience evaluation: a case from mobile news journalism. In: Proc. ECCE '09. VTT, pp. 240-247 (2009)

40. Väätäjä, H.: User experience of smart phones in mobile journalism: early findings on influence of professional role. In: Proc. OZCHI '10. 1-4, ACM (2010) 
41. Väätäjä, H. Männistö, A.A.: Bottlenecks, usability issues and development needs in creating and delivering news videos with smart phones. In: Proc. MoViD '10, pp. 45-50, ACM (2010)

42. Väätäjä, H. Egglestone, P.: Briefing news reporting with mobile assignments: perceptions, needs and challenges. In: Proc. CSCW '12. ACM, 485-494 (2012)

43. Väätäjä, H., Vainio, T. Sirkkunen, E.: Location-based crowdsourcing of hyperlocal news: dimensions of participation preferences. In: Proc. GROUP '12. ACM, 85-94 (2012)

44. Jokela, T., Väätäjä, H., Koponen, T.: Mobile Journalist Toolkit: A field study on producing news articles with a mobile device. In: Proc. MindTrek '09. ACM, pp. 45-52, ACM (2009)

45. Koponen, T., Väätäjä, H. 2009. Early adopters' experiences of using mobile multimedia phones in news journalism. In: Proc. ECCE '09, VTT, 4 pages (2009)

46. Väätäjä, H., Männistö, A., Vainio, T., Jokela, T.: Understanding User Experience to Support Learning for Mobile Journalist's Work. In: R. Guy (ed.) The Evolution of Mobile Teaching and Learning. Informing Science Press, 2009, pp. 177-210. Available at https://books.google.fi/books?isbn=1932886141

47. Väätäjä, H., Sirkkunen, E., Ahvenainen, M.: A field trial on mobile crowdsourcing of news content - Factors influencing participation. In: Human-Computer Interaction - INTERACT 2013, LNCS, vol 8119, pp. 54-73 (2013)

48. Yurdusev, A. N.: 'Level of Analysis' and'Unit of Analysis': A Case for Distinction. Millennium-Journal of International Studies, 22(1), 77-88 (1993) 